\title{
Neural substrates mediating context-dependent sensitization to psychostimulants
}

\author{
MITSUO NAKAMURA, KEN BELL, JENNIFER L. CORNISH, and PETER W. KALIVAS \\ Washington State University, Pullman, Washington
}

\begin{abstract}
Exposure to a context previously associated with psychostimulants administration can elicit behavioral activation that partially mimics the psychostimulant-induced response or augments psychostimulant-induced motor activity. This interaction between the environment and the behavioral effect of psychostimulants is known as context-dependent sensitization or drug-induced conditioned locomotor activity. Although the neural substrates underlying context-dependent sensitization remain unknown, recent studies have suggested that behavioral sensitization to psychostimulants may be mediated, in part, by a context-conditioned augmentation in glutamate transmission in the projection from the prefrontal cortex and/or amygdala to the nucleus accumbens. In contrast, while dopamine transmission in the nucleus accumbens is clearly involved in the unconditioned response to the acute or repeated administration of psychostimulants, it seems less likely that it mediates the context-dependent effects of cocaine.
\end{abstract}

Repeated intermittent administration of amphetaminelike psychostimulants is frequently associated with a progressive increase in the locomotor response to subsequent drug challenge that is called behavioral sensitization (Kalivas \& Stewart, 1991; Robinson \& Becker, 1986). Exposure to a context previously associated with psychostimulants administration can elicit behavioral activation that partially mimics the psychostimulant-induced response (Beninger \& Hahn, 1983; Martin-Iverson \& McManus, 1990; Martin-Iverson \& Reimer, 1994) or augments psychostimulant-induced motor activity (Fontana, Post, \& Pert, 1993; Hinson \& Poulos, 1981; Post, Lockfeld, Squillace, \& Contel, 1981 ; Weiss, Post, Pert, Woodward, \& Murman, 1989). This interaction between the environment and the behavioral effect of psychostimulants is known as context-dependent sensitization or drug-induced conditioned locomotor activity. This phenomenon has been explained as a classical conditioning process in which psychostimulants act as an unconditioned stimulus, and contexts associated with repeated drug administration act as conditioned stimuli (Stewart \& Vezina, 1988).

It has been shown that processes underlying contextindependent sensitization are probably separable from those that underlie context-dependent sensitization (Stewart \& Druhan, 1993). For example, the extinction of conditioned activity does not abolish the subsequent expression of sensitization to the drug effect (Stewart \& Vezina, 1991 ). In addition, the sensitization that develops following repeated intracranial injection of amphetamine to the ventral tegmental area is independent of context and does

Correspondence concerning this article should be addressed to M. Nakamura, Department of Physiology/Neuroscience, Medical University of South Carolina, 650 MUSC Complex, Suite 607, Charleston, SC 29425 (e-mail: nakamura@musc.edu). not come under the control of environmental stimuli associated with the injections (Vezina \& Stewart, 1990).

Augmented dopamine transmission in the nucleus accumbens to a psychostimulant challenge may be a primary process of context-independent sensitization (Kalivas \& Stewart, 1991; Robinson \& Becker, 1986; White, Xiu, Henry, \& Zhang, 1995). The enhanced releasability of dopamine is manifest not only in vivo (Akimoto, Hamamura, Kazahaya, Akiyama, \& Otsuki, 1990; Heidbreder, Thompson, \& Shippenberg, 1996; Kalivas \& Duffy, 1993; Robinson \& Whishaw, 1988; Wolf, White, Nassar, Brooderson, \& Khansa, 1993) but in tissue slices and synaptosomes obtained from the striatum and nucleus accumbens (Castaneda, Becker, \& Robinson, 1988; Kolta, Shreve, De Souza, \& Uretsky, 1985; Kolta, Shreve, \& Uretsky, 1989; Peris et al., 1990; Robinson \& Becker, 1982; Wilcox, Robinson, \& Becker, 1986). Likewise, enhanced postsynaptic responsiveness to dopamine has been demonstrated in vivo and in vitro in animals pretreated with repeated injections of psychostimulants (Henry \& White, 1991; Higashi, Inanaga, Nishi, \& Uchimura, 1989; Nestler, Hope, \& Widnell, 1993). Although the neural substrates underlying context-dependent sensitization remain unknown, recent studies have suggested that long-term neuroadaptations in glutamate transmission in corticofugal projections to the nucleus accumbens may be important (Pierce \& Kalivas, 1997). In this paper, we will describe the potential involvement of changes in dopamine and glutamate neurotransmission in context-dependent sensitization.

\section{Changes of Dopamine Transmission in the Nucleus Accumbens}

Many behavioral studies have implicated dopamine transmission in the nucleus accumbens as having a role in the conditioned locomotor response to psycho- 
stimulants. Thus, it has been found that systemic coadministration of the $D_{2}$ antagonist pimozide can block the development of conditioned activity based on the pairing of an environment with amphetamine (Beninger \& Hahn, 1983) or cocaine (Beninger \& Herz, 1986). Also, rats repeatedly treated with cocaine in the test environment ( $10 \mathrm{mg} / \mathrm{kg}$, i.p., 10 days) have been found to show a greater response to the intra-accumbens microinjection of amphetamine than have subjects that received cocaine in the home cage (Post, Weiss, \& Pert, 1988). In contrast, there was no difference between the two groups following a challenge microinjection of amphetamine into the caudate nucleus. In addition, bilateral dopamine depletion in the nucleus accumbens induced by 6-hydroxydopamine (more than $60 \%$ dopamine depletion) has been found to block the conditioned locomotor response to amphetamine (Gold, Swerdlow, \& Koob, 1988). On the basis of these observations, it was hypothesized that mesolimbic dopamine neurotransmission is a necessary requirement for the development of amphetamineconditioned locomotion (Gold et al., 1988).

In apparent support of these behavioral data, conditioned stimuli paired with a large dose of cocaine (40 $\mathrm{mg} / \mathrm{kg}$, i.p.) for one training session have elicited significant increases in both locomotor activity and extracellular dopamine in the nucleus accumbens of rats during a second test session with a low dose of cocaine $(10 \mathrm{mg} / \mathrm{kg}$, i.p.; Fontana et al., 1993). Also, it has been reported that the administration of saline to animals pretreated with repeated injections of cocaine elicited a small increase in extracellular dopamine in the nucleus accumbens (Kalivas \& Duffy, 1990). However, other neurochemical studies have not yielded such an increase in extracellular dopamine by conditioned stimuli. Brown and Fibiger (1992) found that repeated administration of cocaine $(10 \mathrm{mg} / \mathrm{kg}$ $\times 7$ days) in association with a specific environment produced significant locomotion in that environment, but there was no concomitant conditional increase in dopamine release. This finding is consistent with a previous report by Barr et al. (1983), who found that presentation of conditioned stimuli associated with the drug injection elicited behaviors similar to those induced by the drug itself, but noted an absence of conditional neurochemical changes in the dopamine metabolites. Brown and Fibiger (1992) suggested that although the development of cocaine-induced, environment-specific conditioning is dopamine dependent, the neurochemical events associated with the expression of the conditioned response are not dependent on dopamine transmission.

\section{Changes of Glutamate Transmission in the Nucleus Accumbens}

Rather than directly measuring neurotransmission, a different approach to determine the neural substrates mediating the conditioned effects of psychostimulants is to evaluate activation of brain nuclei by exposure to a conditioned stimulus with and without drug challenge. These studies have demonstrated that nondopaminergic neural circuits are recruited in the unconditioned and conditioned effects of cocaine (Breiter et al., 1997; Brown, Robertson, \& Fibiger, 1992; Childress et al., 1999; Grant et al., 1996). Using Fos immunohistochemistry as a marker for cellular activation, Brown et al. (1992) revealed that exposure of rats to a cocaine-paired environment produced an increase in locomotion and in Fos expression within specific limbic regions such as the cingulate cortex, claustrum, lateral septal nucleus, paraventricular nucleus of the thalamus, lateral habenula, and amygdala. However, in contrast to increases in Fos in the nucleus accumbens that accompany an acute injection of cocaine (Daunais \& McGinty, 1994; Moratalla, Vickers, Robertson, Cochran, \& Graybiel, 1993), no conditional activation of Fos expression was observed within any compartment of the nucleus accumbens. Furthermore, imaging studies in cocaine addicts showed increased glucose uptake or oxygen utilization in cortical and limbic regions, but not in the nucleus accumbens when the addicts were exposed to drug-related stimuli (Childress et al., 1999; Grant et al., 1996). Similar to the findings in preclinical studies outlined above in which Fos expression was used as a marker of cellular activation, in addition to activating some cortical and limbic areas, exposure to the unconditioned stimulus (i.e., a cocaine injection) increased activation of the nucleus accumbens in cocaine addicts (Breiter et al., 1997).

Correlations of metabolic increases in the dorsolateral prefrontal cortex, medial temporal lobe (amygdala), and cerebellum with self-reports of craving have suggested that a distributed neural network which integrates emotional and cognitive aspects of memory links environmental cues with cocaine craving (Childress et al., 1999; Grant et al., 1996). In direct support of the importance of activation of this type of circuit in the long-term neuroadaptations to repeated psychostimulants, lesions of the amygdala have prevented the reinstatement of cocaine self-administration to a contextual cue (Meil \& See, 1997), as well as cocaine-induced conditioned place preference (Brown \& Fibiger, 1993). Also, the expression of behavioral sensitization to a cocaine challenge in rats has been blocked by excitotoxic lesions of the dorsal prefrontal cortex (Pierce, Reeder, Hicks, Morgan, \& Kalivas, 1998).

Although the Fos and imaging studies indicate that exposure to conditional cues appears to activate limbic and cortical structures, the involvement of the nucleus accumbens may still be critical. Many of the cortical regions activated by psychostimulant conditioned cues, including the amygdala and prefrontal cortex, have glutamatergic projections to the nucleus accumbens (Berendse, Galisde Graaf, \& Groenewegen, 1992; Brog, Salyapongse, Deutch, \& Zahm, 1993; Wright, Beijer, \& Groenewegen, 1996; Wright \& Groenewegen, 1996). This raises the possibility that increasing activity in corticofugal glutamatergic projections to the nucleus accumbens may be critical for the context-induced expression of psychostimulant-like behaviors (Pierce \& Kalivas, 1997). Recent studies have shown that the capacity of cocaine to in- 


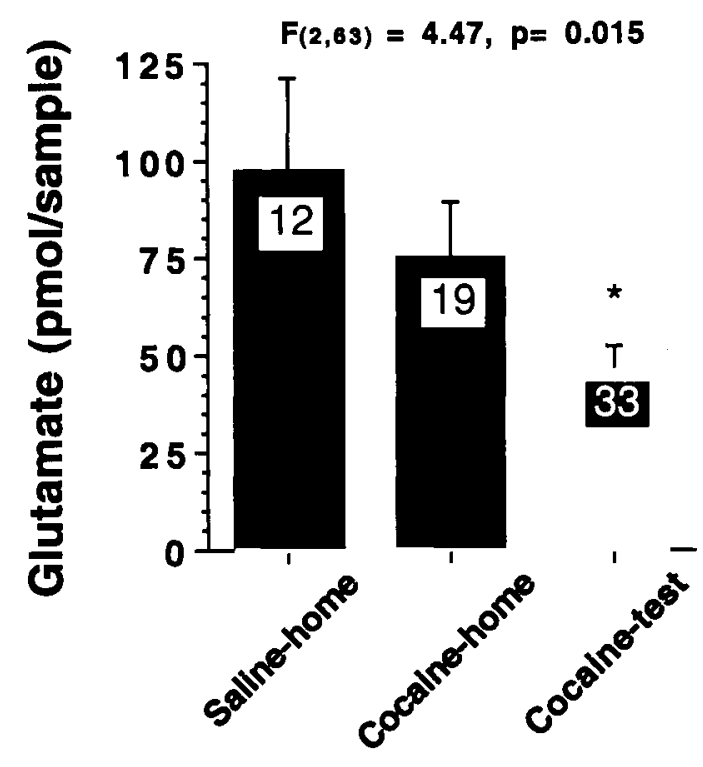

Figure 1. Reduction in basal levels of extracellular glutamate by exposure to the environmental context associated with daily cocaine administration. See Kalivas and Duffy (1995) for the glutamate dialysis and quantification procedures. Briefly, all rats were placed into a dialysis apparatus and connected to the dialysis probe carrier without inserting a dialysis probe through the guide cannula. Two hours later, saline-home rats were disconnected from the dialysis probe connector, injected with saline $(1.0 \mathrm{ml} / \mathrm{kg}$, i.p.) and returned to the home cage. The cocaine-home subjects were disconnected from the dialysis probe connector, injected with cocaine $(15 \mathrm{mg} / \mathrm{kg}$, i.p.), and returned to the home cage. The cocaine-test animals were kept attached to the dialysis probe connector, injected with cocaine $(15 \mathrm{mg} / \mathrm{kg}$, i.p.), and returned to the dialysis apparatus for an additional $3 \mathrm{~h}$. This procedure continued for 5 days. Two weeks later, all subjects were placed in the dialysis apparatus and a dialysis probe was inserted into the nucleus accumbens through the indwelling guide cannula. The next morning, five $\mathbf{2 0}$-min baseline samples were collected. Glutamate levels from the five samples were averaged. The data are shown as the mean $(+S E M)$ extracellular glutamate levels and were statistically evaluated in a one-way analysis of variance followed by a Dunnett's test for comparison with saline-home. The number of determinations in each group is shown within the bar. ${ }^{\star} p<.05$, compared with saline-home.

crease extracellular glutamate in the nucleus accumbens is augmented in rats behaviorally sensitized to repeated injections of cocaine (Pierce, Bell, Duffy, \& Kalivas, 1996; Reid \& Berger, 1996). Moreover, the augmentation in extracellular glutamate in the core of the nucleus accumbens is abolished by excitotoxic lesions of the dorsal prefrontal cortex (Pierce et al., 1998), and it occurs only in rats that have developed behavioral sensitization, not in subjects treated with the same repeated dosing regimen of cocaine that do not express significant sensitization (Pierce et al., 1996). The importance of this enhanced glutamate release in behavioral sensitization is indicated by the fact that the expression of cocaine sensitization was abolished by pretreatment of the core of the nucleus accumbens with the non-NMDA antagonist, 6-cyano-7nitroquinoxaline-2,3-dione (CNQX; Pierce et al., 1998).
In addition to the apparent augmentation in presynaptic glutamate transmission in animals sensitized to repeated cocaine, there is evidence of an accompanying increase in postsynaptic responsiveness at the AMPA glutamate receptor. Pierce et al. (1996) demonstrated an enhanced behavioral response to the microinjection of AMPA into the core of the nucleus accumbens in animals pretreated with daily cocaine, and Churchill, Ghasemzadeh, and Kalivas (1997) found that the immunoreactive level of the AMPA receptor subunit GluR 1 was augmented in the nucleus accumbens of rats pretreated with daily cocaine injections. Moreover, the enhanced response to AMPA and the increase in GluR 1 content occurred only in animals that developed behavioral sensitization and not in subjects given the same daily cocaine injection regimen that did not display sensitization (Churchill et al., 1997; Pierce et al., 1996).

The presence of cross-sensitization with AMPA only in a subpopulation of rats treated with daily cocaine led Bell and Kalivas (1996) to determine whether or not variability in extent of involvement of learned associations with environmental cues may control the expression of AMPA cross-sensitization with cocaine. These authors observed that the cross-sensitization between repeated cocaine and a subsequent AMPA microinjection into the core of the nucleus accumbens was present only when cocaine was administered daily in the test apparatus and not when cocaine was administered daily in the home cage. Moreover, the increase in GluR1 subunit suggested that there might be a reduction in the basal levels of extracellular glutamate that is producing a compensatory increase in postsynpatic receptor synthesis (Churchill et al., 1997). Indeed, Pierce et al. (1996) reported a 30\%, yet nonsignificant, reduction in basal levels of extracellular glutamate in animals pretreated with daily cocaine. The experiment illustrated in Figure 1 was conducted to determine whether or not context conditioning may be significant in regulating the basal levels of extracellular glutamate. It can be seen that rats receiving cocaine daily in the test dialysis chamber showed a significant reduction in basal extracellular glutamate compared with animals given daily cocaine injections in the home cage or subjects treated with daily saline.

\section{Conclusions}

Taken together, these results suggest that behavioral sensitization to psychostimulants may be mediated, in part, by a context-conditioned augmentation in glutamate transmission in the projection from the prefrontal cortex and/or amygdala to the nucleus accumbens. In contrast, although dopamine transmission in the nucleus accumbens is clearly involved in the unconditioned response to the acute or repeated administration of psychostimulants, it seems less likely that it mediates the context-dependent effects of cocaine. Figure 2 illustrates this proposed situation. While repeated administration of psychostimulants produces long-term changes in preand postsynaptic dopamine transmission in the nucleus 


\section{ACUTE COCAINE Context- independent (dopamine) \\ Context- \\ dependent \\ (glutamate/cortex)}

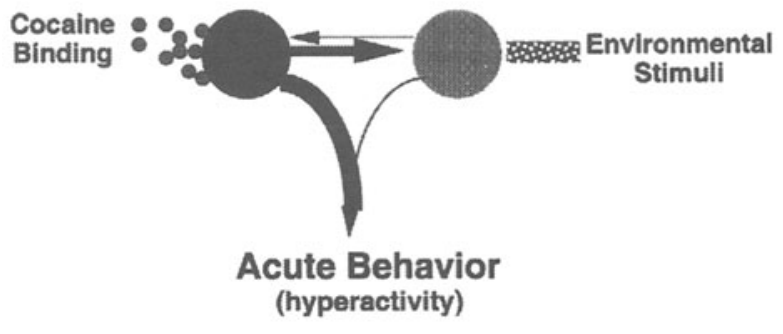

REPEATED COCAINE Contextindependent (dopamine)
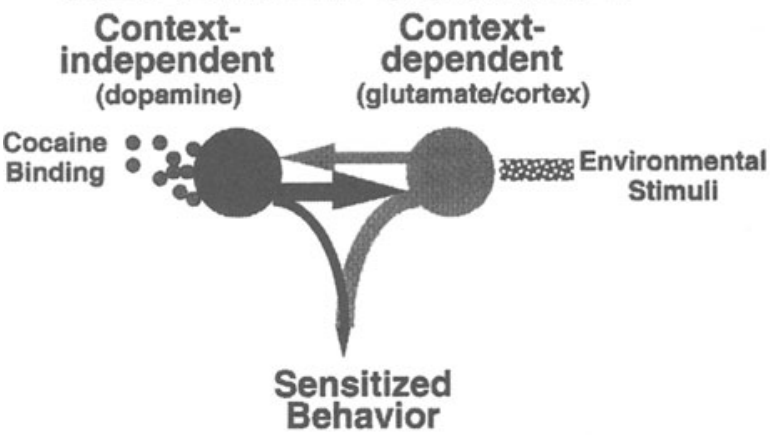

Figure 2. Model of the changes in glutamate and dopamine transmission induced by acute and repeated (sensitized) cocaine administration. Acute cocaine injection increases dopamine transmission in the nucleus accumbens and cortex, which mediates the acute behavioral effect of cocaine. Following repeated administration in association with an environmental context, glutamate transmission is recruited, resulting in elevated glutamate release in the nucleus accumbens, as well as an enhancement in the behavioral response to a drug challenge (sensitization). Cocaine-induced changes of glutamate neurotransmission in the nucleus accumbens may permit enhanced dopamine, through an as yet unidentified mechanism, to mediate augmented locomotor activity.

accumbens, the presence of paired environmental cues with the psychostimulant experience results in the recruitment of cortical circuitry and the subsequent activation of glutamate transmission in the nucleus accumbens. Further evidence of this fact is the recent finding of Cornish, Duffy, and Kalivas (1997) that the stimulation of AMPA receptors in the core of the nucleus accumbens reinstates behavioral responding indicative of cocaine-seeking behavior. This is similar to the effect of presentation of a conditioned cue on the reinstatement of responding on a lever previously paired with intravenous cocaine (Meil \& See, 1997), and it indicates that the stimulation of glutamate transmission in the nucleus accumbens may mimic exposure to environmental stimuli associated with chronic cocaine administration.

\section{REFERENCES}

Akimoto, K., Hamamura, T., Kazahaya, Y., Akiyama, K., \& OTsuKI, S. (1990). Enhanced extracellular dopamine level may be the fundamental neuropharmacological basis of cross-behavioral sensitization between methamphetamine and cocaine - an in vivo dialysis study in freely moving rats. Brain Research, 507, 344-346.

Barr, G. A., Sharpless, N. S., Cooper, S., Schiff, S. R., Paredes, W., \& BRIDGER, W. H. (1983). Classical conditioning, decay and extinction of cocaine-induced hyperactivity and stereotypy. Life Sciences, 33, 1341-1351.

BeLL, K., \& Kalivas, P. W. (1996). Context-specific cross-sensitization between systemic cocaine and intra-accumbens AMPA infusion in the rat. Psychopharmacology, 127, 377-383.

BENINGER, R. J., \& HAHN, B. L. (1983). Pimozide blocks establishment but not expression of amphetamine-produced environment-specific conditioning. Science, 220, 1304-1306.

Beninger, R. J., \& Herz, S. (1986). Pimozide blocks establishment but not expression of cocaine-produced environment-specific conditioning. Life Sciences, 38, 1425-1431.

BerEndse, H. W., Galis-de GraAf, Y., \& Groenewegen, H. J. (1992). Topographical organization and relationship with ventral striatal compartments of prefrontal corticostriatal projections in the rat. Journal of Comparative Neurology, 316, 314-347.

Breiter, H. C., Gollub, R. L., Weisskoff, R. M., Kennedy, D. N., MaKris, N., Berke, J. D., Goodman, J. M., Kantor, H. L., GastFriend, D. R., Riorden, J. P., Mathew, R. T., Rosen, B. R., \& HyMAN, S. E. (1997). Acute effects of cocaine on human brain activity and emotion. Neuron, 19, 591-611.

Brog, J. S., Salyapongse, A., Deutch, A. Y., \& Zahm, D. S. (1993). The patterns of afferent innervation of the core and shell in the "accumbens" part of the ventral striatum: Immunohistochemical detection of retrogradely transported Fluoro-Gold. Journal of Comparative Neurology, 338, 255-278.

Brown, E. E., \& Fibiger, H. C. (1992). Cocaine-induced conditioned locomotion: Absence of associated increases in dopamine release. Neuroscience, 48, 621-629.

Brown, E. E., \& FIBIGER, H. C. (1993). Differential effects of excitotoxic lesions of the amygdala on cocaine-induced conditioned locomotion and conditioned place preference. Psychopharmacology, 113, 123-130.

Brown, E. E., Robertson, G. S., \& Fibiger, H. C. (1992). Evidence for conditional neuronal activation following exposure to a cocainepaired environment: Role of forebrain limbic structures. Journal of Neuroscience, 12, 4112-4121.

Castaneda, E., Becker, J. B., \& Robinson, T. E. (1988). The longterm effects of repeated amphetamine treatment in vivo on amphetamine, $\mathrm{KCl}$ and electrical stimulation evoked striatal dopamine release in vitro. Life Sciences, 42, 2447-2456.

Childress, A. R., Mozley, P. D., McElgin, W., Fitzgerald, J., ReIvich, M., \& O'Brien, C. P. (1999). Limbic activation during cueinduced cocaine craving. American Journal of Psychiatry, 156, 11-18.

Churchill, L., Ghasemzadeh, M. B., \& Kalivas, P. W. (1997). Glutamate receptor subunits (GluR1 and NMDAR1) increase in the nucleus accumbens of rats 3 weeks after repeated cocaine exposure. Society for Neuroscience Abstracts, 23, 260.

CoRnish, J. L., Duffy, P., \& Kalivas, P. W. (1997). The effect of glutamatergic drugs on the maintenance and reinstatement of cocaine self-administration behavior. Society for Neuroscience Abstracts, $\mathbf{2 3}$, 261.

DAUNAIS, J. B., \& McGiNTY, J. F. (1994). Acute and chronic cocaine administration differentially alters striatal opioid and nuclear transcription factor mRNAs. Synapse, 18, 35-45.

Fontana, D. J., Post, R. M., \& Pert, A. (1993). Conditioned increases in mesolimbic dopamine overflow by stimuli associated with cocaine. Brain Research, 629, 31-39.

Gold, L. H., Swerdlow, N. R., \& Коов, G. F. (1988). The role of mesolimbic dopamine in conditioned locomotion produced by amphetamine. Behavioral Neuroscience, 102, 544-552. 
Grant, S., London, E. D., Newlin, D. B., Villemagne, V. L., Liu, X. Contoreggi, C., Phillips, R. L., Kimes, A. S., \& Margolin, A. (1996). Activation of memory circuits during cue-elicited cocaine craving. Proceedings of the National Academy of Sciences, 93 , 12040-12045.

Heidbreder, C. A., Thompson, A. C., \& Shippenberg, T. S. (1996). Role of extracellular dopamine in the initiation and long-term expression of behavioral sensitization to cocaine. Journal of Pharmacology \& Experimental Therapeutics, 278, 490-502.

HENRY, D. J., \& WhiTE, F. J. (1991). Repeated cocaine administration causes persistent enhancement of D1 dopamine receptor sensitivity within the rat nucleus accumbens. Journal of Pharmacology \& Experimental Therapeutics, 258, 882-890.

Higashi, H., Inanaga, K., Nishi, S., \& Uchimura, N. (1989). Enhancement of dopamine actions on rat nucleus accumbens neurones in vitro after methamphetamine pretreatment. Journal of Physiology, 408, 587-603.

Hinson, R. E., \& Poulos, C. X. (1981). Sensitization to the behavioral effects of cocaine: Modification by Pavlovian conditioning. Pharmacology, Biochemistry \& Behavior, 15, 559-562.

Kalivas, P. W., \& DuFFY, P. (1990). Effect of acute and daily cocaine treatment on extracellular dopamine in the nucleus accumbens. Synapse, 5, 48-58.

Kalivas, P. W., \& DufFy, P. (1993). Time course of extracellular dopamine and behavioral sensitization to cocaine: II. Dopamine perikarya. Journal of Neunoscience, 13, 276-284.

Kalivas, P. W., \& DufFY, P. (1995). D1 receptors modulate glutamate transmission in the ventral tegmental area. Journal of Neuroscience, $15,5379-5388$.

Kalivas, P. W., \& Stewart, J. (1991). Dopamine transmission in the initiation and expression of drug- and stress-induced sensitization of motor activity. Brain Research Reviews, 16, 223-244.

Kolta, M. G., Shreve, P., De Souza, V., \& URetsky, N. J. (1985). Time course of the development of the enhanced behavioral and biochemical responses to amphetamine after pretreatment with amphetamine. Neuropharmacology, 24, 823-829.

Kolta, M. G., Shreve, P., \& URETSKY, N. J. (1989). Effect of pretreatment with amphetamine on the interaction between amphetamine and dopamine neurons in the nucleus accumbens. Neuropharmacology, 28, 9-14.

Martin-Iverson, M. T., \& McManus, D. J. (1990). Stimulantconditioned locomotion is not affected by blockade of $D_{1}$ and/or $D_{2}$ dopamine receptors during conditioning. Brain Research, 521, $175-$ 184.

Martin-Iverson, M. T., \& Reimer, A. R. (1994). Effect of nimodipine and/or haloperidol on the expression of conditioned locomotion and sensitization to cocaine in rats. Psychopharmacology, 114, 315-320.

MEIL, W. M., \& SEE, R. E. (1997). Lesions of the basolateral amygdala abolish the ability of drug associated cues to reinstate responding during withdrawal from self-administered cocaine. Behavioural Brain Research, 87, 139-148.

Moratalla, R., Vickers, E. A., Robertson, H. A., Cochran, B. H., \& Graybiel, A. M. (1993). Coordinate expression of c-fos and jun $B$ is induced in the rat striatum by cocaine. Journal of Neuroscience, $13,423-433$

Nestler, E. J., Hope, B. T., \& Widnell, K. L. (1993). Drug addiction: A model for the molecular basis of neural plasticity. Neumn, 11, $995-$ 1006

Peris, J., Boyson, S. J., Cass, W. A., Curella, P., Dwoskin, L. P., Larson, G., Lin, L.-H., Yasuda, R. P., \& Zahniser, N. R. (1990). Persistence of neurochemical changes in dopamine systems after repeated cocaine administration. Journal of Pharmacology \& Experimental Therapeutics, 253, 38-44.

Pierce, R. C., Bell, K., Duffy, P., \& Kalivas, P. W. (1996). Repeated cocaine augments excitatory amino acid transmission in the nucleus accumbens only in rats having developed behavioral sensitization. Journal of Neuroscience, 16, 1550-1560.

Pierce, R. C., \& Kalivas, P. W. (1997). A circuitry model of the expression of behavioral sensitization to amphetamine-like psychostimulants. Brain Research Reviews, 25, 192-216.
Pierce, R. C., Reeder, D. C., Hicks, J., Morgan, Z. R., \& Kalivas, P. W. (1998). Ibotenic acid lesions of the dorsal prefrontal cortex disrupt the expression of behavioral sensitization to cocaine. Neuroscience, $\mathbf{8 2}$, 1103-1114.

Post, R. M., Lockfeld, A., SQuillace, K. M., \& Contel, N. R. (1981). Drug-environment interaction: Context dependency of cocaine-induced behavioral sensitization. Life Sciences, 28, 755-760.

Post, R. M., Weiss, S. R. B., \& Pert, A. (1988). Cocaine-induced behavioral sensitization and kindling: Implications for the emergence of psychopathology and seizures. In P. W. Kalivas \& C. B. Nemeroff (Eds.), The mesocorticolimbic dopamine system (Annals of the New York Academy of Sciences, Vol. 537, pp. 292-308). New York: New York Academy of Sciences.

REID, M. S., \& BERGER, S. P. (1996). Evidence for sensitization of cocaine-induced nucleus accumbens glutamate release. NeuroReport, 7, 1325-1329.

RoBinson, T. E., \& BECKER, J. B. (1982). Behavioral sensitization is accompanied by an enhancement in amphetamine-stimulated dopamine release from striatal tissue in vitro. European Journal of Pharmacology, 85, 253-254.

ROBINSON, T. E., \& BECKER, J. B. (1986). Enduring changes in brain and behavior produced by chronic amphetamine administration: A review and evaluation of animal models of amphetamine psychosis. Brain Research Reviews, 11, 157-198.

RoBINSON, T. E., \& Whishaw, I. Q. (1988). Normalization of extracellular dopamine in the striatum following recovery from a partial unilateral 6-OHDA lesion of the substantia nigra: A microdialysis study in freely moving rats. Brain Research, 450, 209-224.

Stewart, J., \& Druhan, J. P. (1993). Development of both conditioning and sensitization of the behavioral activating effects of amphetamine is blocked by the non-competitive NMDA receptor antagonist, MK-801. Psychopharmacology, 110, 125-132.

Stewart, J., \& Vezina, P. (1988). Conditioning and behavioral sensitization. In P. W. Kalivas \& C. D. Barnes (Eds.), Sensitization in the nervous system (pp. 207-224). Caldwell, NJ: Telford Press.

STEWART, J., \& VEZINA, P. (1991). Extinction procedures abolish conditioned stimulus control but spare sensitized responding to amphetamine. Behavioural Pharmacology, 2, 65-71.

Vezina, P., \& Stewart, J. (1990). Amphetamine administered to the ventral tegmental area but not to the nucleus accumbens sensitizes rats to systemic morphine: Lack of conditioned effects. Brain Research, 516, 99-106.

Weiss, S. R. B., Post, R. M., Pert, A., Woodward, R., \& Murman, D (1989). Context-dependent cocaine sensitization: Differential effect of haloperidol on development versus expression. Pharmacology, Biochemistry \& Behavior, 34, 655-661.

White, F. J., XiU, Y.-H., Henry, D. J., \& Zhang, X.-F. (1995). Neurophysiological alterations in the mesocorticolimbic dopamine system during repeated cocaine administration. In R. Hammer (Ed.), The neurobiology of cocaine addiction (pp. 99-120). Boca Raton, FL: CRC Press.

Wilcox, R. A., Robinson, T. E., \& Becker, J. B. (1986). Enduring enhancement in amphetamine-stimulated striatal dopamine release in vitro produced by prior exposure to amphetamine or stress in vivo. European Journal of Pharmacology, 124, 375-376

Wolf, M. E., White, F. J., Nassar, R., Brooderson, R. J., \& Khansa, M. R. (1993). Differential development of autoreceptor subsensitivity and enhanced dopamine release during amphetamine sensitization. Journal of Pharmacology \& Experimental Therapeutics, 264, 249-255.

Wright, C. I., BeiJer, A. V., \& Groenewegen, H. J. (1996). Basal amygdaloid complex afferents to the rat nucleus accumbens are compartmentally organized. Journal of Neuroscience, 16, 1877-1893.

Wright, C. I., \& Groenewegen, H. J. (1996). Patterns of overlap and segregation between insular cortical, intermediodorsal thalamic and basal amygdaloid afferents in the nucleus accumbens of the rat. Neuroscience, $73,359-373$.

(Manuscript received August 4, 1998 revision accepted for publication December 21,1998 .) 